\title{
Trypanosoma rangeli expresses a gene of the group II trans-sialidase superfamily ${ }^{\text {is }}$
}

\author{
Néstor Añez-Rojas ${ }^{\mathrm{a}}$, Andreína Peralta ${ }^{\mathrm{b}}$, Gladys Crisante ${ }^{\mathrm{c}}$, Agustina Rojas $^{\mathrm{c}}$, \\ Néstor Añez ${ }^{\mathrm{c}}$, José L. Ramírez ${ }^{\mathrm{b}, \mathrm{d}}$, Miguel A. Chiurillo ${ }^{\mathrm{a}, \mathrm{d}, *}$ \\ ${ }^{a}$ Decanato de Medicina, Universidad Centroccidental Lisandro Alvarado, Barquisimeto, Estado Lara, Venezuela \\ ${ }^{\mathrm{b}}$ Laboratorio de Genética Molecular, Instituto de Biología Experimental, UCV, Caracas, Venezuela \\ c Centro de Investigaciones Parasitológicas "José Francisco Torrealba”, ULA, Mérida, Venezuela \\ ${ }^{\mathrm{d}}$ Centro de Biotecnología, Instituto de Estudios Avanzados (IDEA), Caracas, Venezuela \\ Received 20 January 2005; accepted 22 March 2005 \\ Available online 9 April 2005
}

Keywords: Trypanosoma rangeli; Superfamily gene; trans-sialidase; Telomeric genes

Trypanosoma cruzi, the etiological agent of Chagas disease, and Trypanosoma rangeli, a nonpathogenic protozoa for mammals, present surface glycoproteins of the transsialidase superfamily (TSASF). According to sequence identity, molecular weight, and function [1-3], members of TSASF are classified into four groups. The first group includes $T$. cruzi trans-sialidase (TcTS) and T. rangeli sialidase (TrSial). TrSial expressed in T. rangeli epimastigotes forms is a strict hydrolytic enzyme that releases sialic acid residues from the host cell surface glycoconjugates [4-6]. In contrast, T. cruzi trans-sialidase transfers sialic residues from the host surface onto mucin molecules on the parasite's surface [3]. Although TrSial has been well characterized [4-9], its biological role remains unknown.

Members of group II TSASF, collectively known as gp85 (or gp85/trans-sialidase), are expressed in T. cruzi infective trypomastigotes forms, and intracellular amastigotes stages [1-3]. This group, which has only been described in T. cruzi, includes a set of heterogeneous GPI-anchored surface glycoproteins with similar molecular masses but different electrical

Abbreviations: aa, aminoacids; bp, base pair; CHEF, clamped homogeneous gel electrophoresis; gp 85 , surface glycoprotein of $85 \mathrm{kDa}$; GPI, glycosylphosphatidylinositol; kb, kilobase; kDa, kilodaltons; TBS, Tris-buffered saline; TcTS, active trans-sialidase of T. cruzi; TrSial, sialidase of T. rangeli; TSA, trans-sialidase

Note: Nucleotide sequence data reported in this paper have been submitted to the GenBank ${ }^{\mathrm{TM}}$ data base with accession number AF426022.

* Corresponding author. Fax: +58 2512591918.

E-mail address: mchiurillo@ucla.edu.ve (M.A. Chiurillo). charges. gp85/trans-sialidase proteins have been implicated in adhesion and/or internalization of the parasite to host cells $[10,11]$, but none of its members have sialidase or transsialidase activity.

In a previous work, we cloned telomeric sequences from a $T$. rangeli [12]. One of the recombinants obtained, namely TrTel 4 (3376 bp), had an ORF with high percent identity with all members of the gp85/trans-sialidase family at $1 \mathrm{~kb}$ from the telomeric end, and with the transcription sense oriented from the centromere towards the telomere.

The putative 1953-bp long gene (TrGP) (Fig. 1A) encoded for 651 aminoacids (aa) putative protein with estimated mass of $71 \mathrm{kDa}$. At the nucleotide level, $\operatorname{Tr} G P$ sequence displayed $62-67 \%$ identity (83-96\% in some blocks) with $T$. cruzi gp85/trans-sialidase genes. In addition, the translated sequence of $\operatorname{Tr} G P$ exhibited $45-50 \%$ identity (reaching 60\% considering conservative amino acid substitutions) with proteins encoded by group II TSASF genes [10,13-17], and to a lesser degree (25-30\% identity) with group I members of this superfamily, including $T$. rangeli sialidases (GenBank U83180, L14943). Blocks of sequence identity between TrGP and gp 85 proteins are shown in Fig. 1B.

TrGP shares with all members of the TSASF [3] the following features:

(i) Two conserved copies of the bacterial neuraminidase motif SxDxGxTW (Asp Box) (Fig. 1A and B).

(ii) A partially complete copy of the subterminal element VTVxNVfLYNR (Fig. 1A and B). This motif, known 


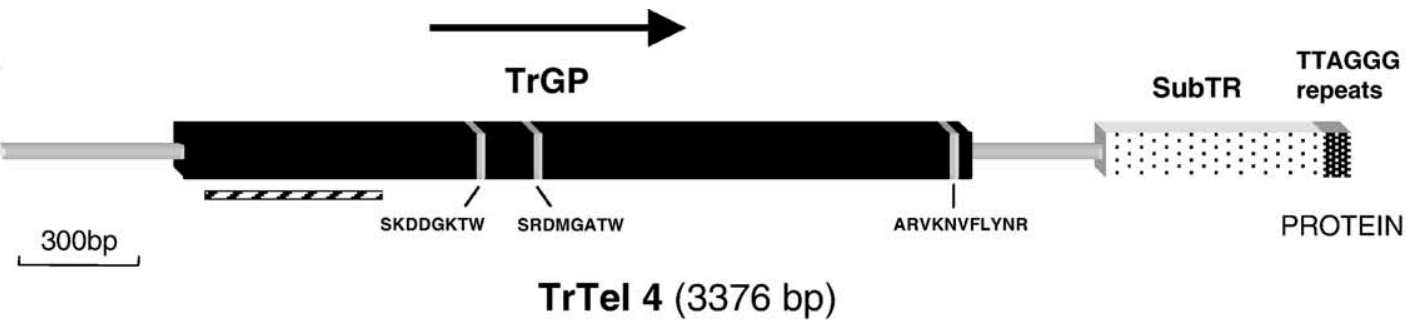

(A)

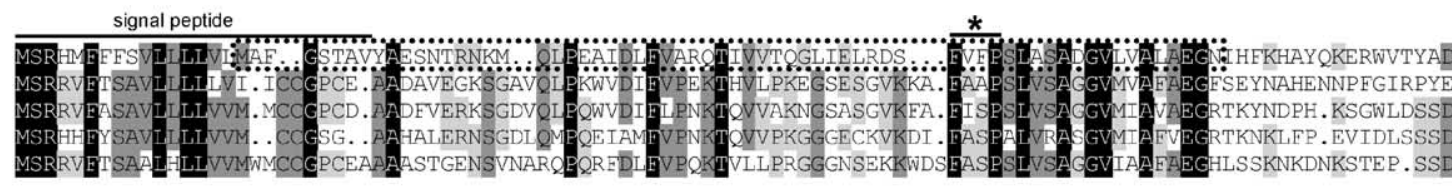

TrGP

TCASP-2

Tcsp-2

TCTSA-E2

TC85KD

$\operatorname{TrGP}$

TCASP-2

Tcsp-2

TCTSA-E2

$\mathrm{TC} 85 \mathrm{KD}$

TrGP

TCASP-2

Tcsp-2

TCTSA-E2

$\mathrm{TC} 85 \mathrm{KD}$
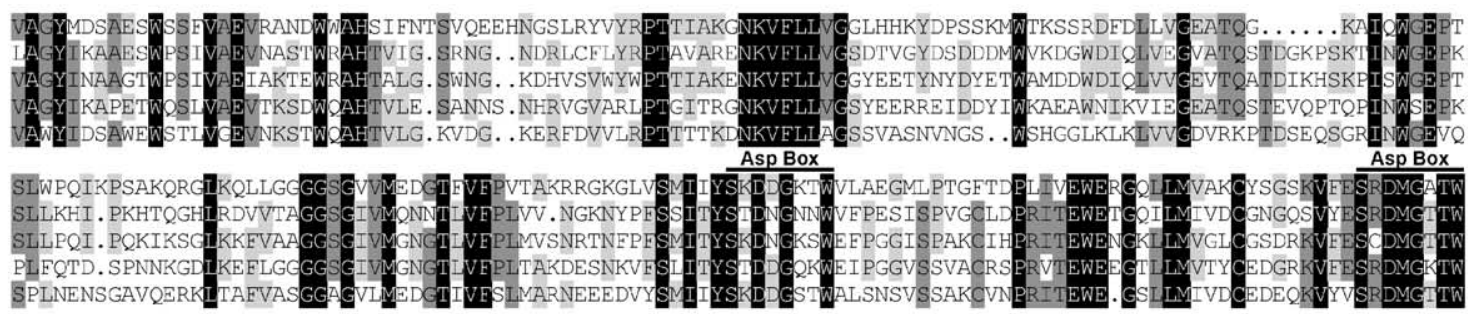

\section{TrGP}

TCASP-2

Tcsp-2

TCTSA-E2

$\mathrm{TC} 85 \mathrm{KD}$
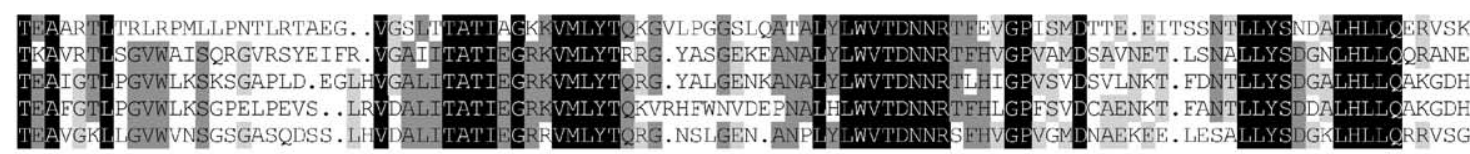

DCAENKT. FANT LLYSDDA LHLLQAKGDH

TrGP

TCASP-2

Tcsp-2

TCTSA-E2

TC85KD

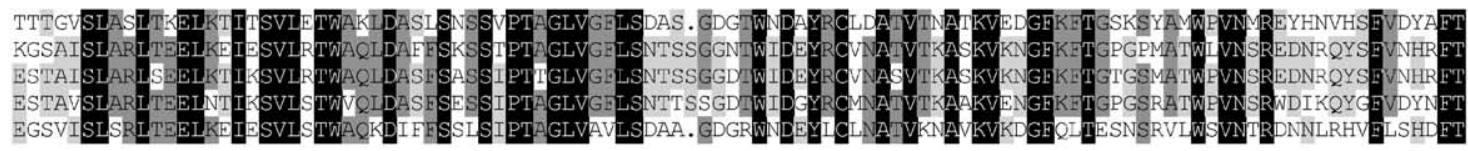

305

310

310

309

311

TrGP

TCASP-2

Tcsp-2

TCTSA-E2

TC85KD

TrGP

TCASP-2

Tcsp-2

TCTSA-E2

TC85KD
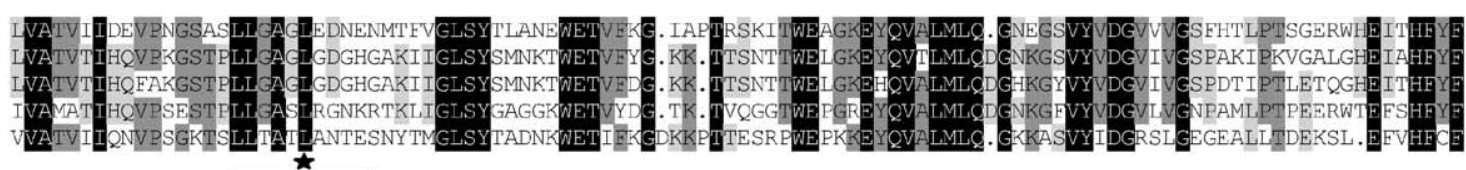

408

Fig. 1. (A) Schematic representation of T. rangeli Trtel 4 clone. Blocks are to indicate major sequence features. Arrows indicate the sense of the coding sequence. Diagonal hatched bar represents TrGP-Nterm probe used in hybridization experiments. SubTR represents subterminal conserved region characteristics of $T$. rangeli telomere [12]. Relative positions of Asp-boxes and VTVxNVfLYNR motifs are shown (thick vertical lines). (B) Clustal W multiple alignment of deduced amino acid sequences from TrGP and four T. cruzi surface proteins of group II of TSA gene superfamily. Sequences are as follows: TrGP (AF426022), TcASP-2* (U77951), Tcsp-2* (AY186573), TcTSA-E2 (U02613) and Tc85KD (M64836). Conserved residues are in black (100\% conservation), dark gray (75\% conservation), and light gray (50\% conservation). Overlining indicates the following motif of $\mathrm{g} p 85 /$ trans-sialidase in the TrGP: a predicted N-terminal signal peptide, two Asp boxes, VTVxNVfLYNR motif $(\star)$, and the partially conserved fRiP sialidase motif $(*)$. Sequence enclosed in pointed line is TrGP ${ }^{\text {Nterm }}$ peptide. In order to improve the alignment, we did not consider a section of 38 amino acids $5^{\prime}$ the N-terminal signal peptide in TcASP-2 and Tcsp-2 sequences.

as peptide $\mathrm{J}$, has been found in gp85 from $T$. cruzi bloodstream trypomastigotes, and it has been implicated in the binding to the mammalian host laminin [10].

(iii) At its $\mathrm{N}$-terminus, it has a signal peptide to direct the protein to the endoplasmatic reticulum that shared a higher percent of identity with $T$. cruzi gp85/trans-sialidase members $(77 \%)$ than with $T$. rangeli sialidase $(45 \%)$ (Fig. 1B).

However, TrGP is devoid of a recognition site for the GPI anchor, a characteristic of many members of TSASF (Fig. 1B). Many residues regarded as important for TrSial 
catalytic activity are absent in TrGP, for instance, the Arg residue in the conserved fRiP element is substituted by an uncharged aa (like T. cruzi gp85/trans-sialidase proteins) (Fig. 1B) $[5,7,8]$. Missing as well, is the N-terminal aa sequence LAPGSS, a characteristic of mature TrSial and TcTS [5].

To study the genomic organization of $\operatorname{Tr} G P$ genes, we carried out Southern blot experiments using a 460-bp probe based on the N-terminal region of the ORF (TrGPNterm). This region was selected for its low nucleotide identity with other TSA superfamily genes. TrGP-Nterm was PCR amplified with the following primers: forward $\left(5^{\prime}\right.$-GTGTTGATGGCCTTTGGC- $\left.3^{\prime}\right)$ and reverse $\left(5^{\prime}\right.$ GTATTTGTGATGCAGGCC-3') (Fig. 1A). Fig. 2A shows the results of hybridizing TrGP-Nterm with T. rangeli (DOG82 strain) genomic DNA digested with several restriction enzymes, the probe recognized many genomic fragments, indicating that $\operatorname{Tr} G P$ related sequences are present in many copies in T. rangeli genome. A similar sample of T. cruzi YBM strain was negative (Fig. 2A, lane 4). Fig. 2B shows a hybridization experiment using TrGP-Nterm probe against $T$. rangeli chromosomal bands separated by pulsed field gel electrophoresis. Confirming the widespread presence of $\operatorname{TrGP}$ in $T$. rangeli genome, the probe recognized most chromosomal bands.

To check for TrGP transcription, we performed Northern blot assays using total RNA isolated from $T$. rangeli epimastigote stage. The result of this experiment revealed that $\operatorname{Tr} G P$ is transcribed in mRNA species of about $4.7 \mathrm{~kb}$ (Fig. 2C). No hybridization was observed with an mRNA fraction isolated from T. cruzi YBM strain epimastigotes (not shown). A positive control consisting of a probe derived from T. cruzi ubiquitin gene, detected mRNA bands in both parasites (not shown).

To check for TrGP translation, we first generated an antiTrGP rabbit antisera using as antigen a recombinant peptide derived from its $\mathrm{N}$-terminal region ( $\left.\mathrm{TrGP}^{\mathrm{Nterm}}\right)$. The 65 aa peptide had low identity with other members of TSA superfamily, including TrSial [4-6]. Briefly, recombinant pET-TrGP ${ }^{\text {Nterm }}$ was constructed as follows: TrGP ${ }^{\text {Nterm }}$ coding sequence was amplified from TrTel 4 recombinant using primers FwNterm (5'-CTTTTAGTGCATATGGCCTTT$3^{\prime}$ ) and RvNterm (5'-TGTTTAAAGCATATGTTACCCT-3'). For the insertion in the expression vector pET-28a (Novagen), NdeI sites were incorporated into both primers. The PCR product was digested with $N d e \mathrm{I}$, and then inserted in-frame in pET-28a plasmid downstream from the region encoding for the initiation codon ATG and $6 \times$ His tag. Recombinant plasmids were transferred to $E$. coli BL21 cells, grown to midlog phase, and finally induced with IPTG. After incubation for $3 \mathrm{~h}$, protein expression was checked in cell extracts using SDS-PAGE. In the gels, a peptide with an apparent molecular mass of $6.9 \mathrm{kDa}$ was observed; this peptide was purified with the B-PER ${ }^{\circledR}$ purification kit (PIERCE), and then used to immunize two rabbits as previously described [18]. Rabbit antiserum reactivity and specificity was tested in Western blotting experiments using epimastigotes cell lysates from

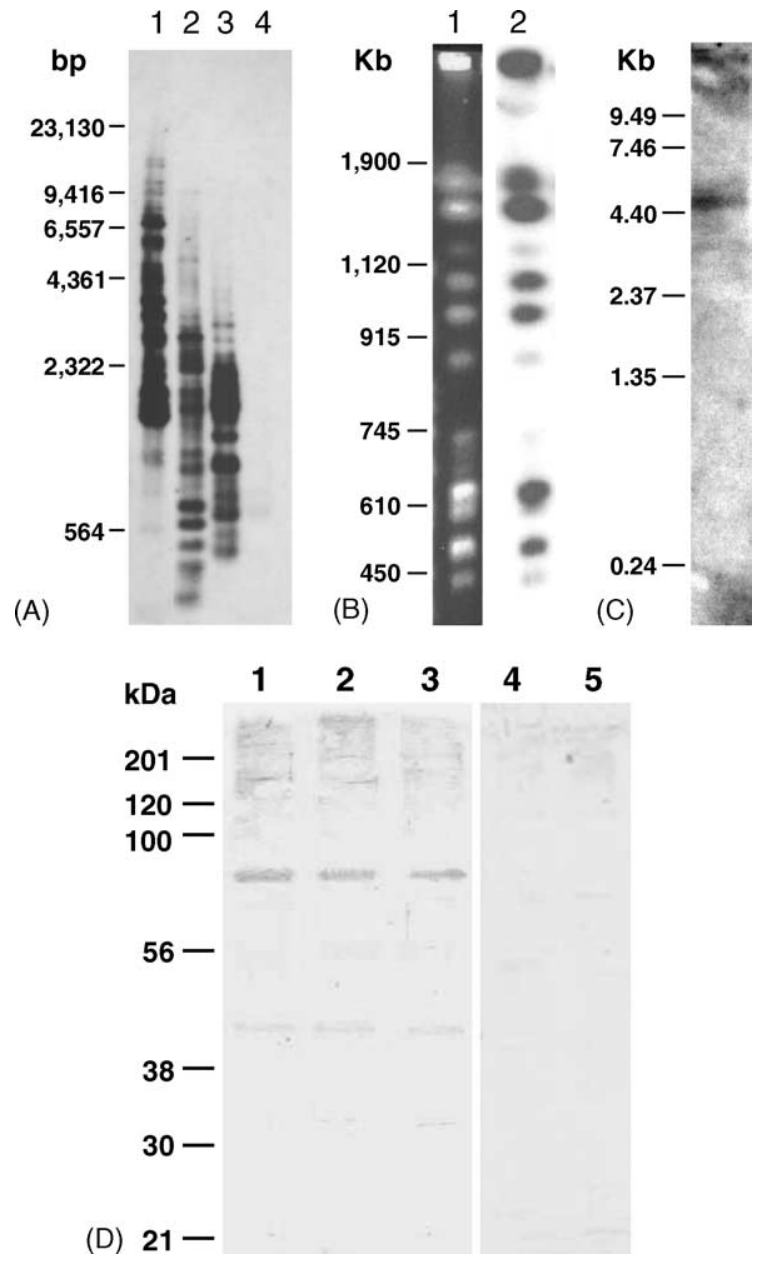

Fig. 2. Genomic organization and expression of $\operatorname{Tr} G P$. All the hybridization analyses were carried out with the ${ }^{32} \mathrm{P}$-labelled TrGP-Nterm probe at high stringency conditions as previously described [19]. (A) Identification of $\operatorname{Tr} G P$ sequences in $T$. rangeli genomic DNA by Southern blot. Lanes 1-3, T. rangeli DNA digested with PstI, RsaI and Sau3AI, respectively; lane 4, T. cruzi DNA digested with Sau3AI. Molecular sizes in kilobases (kb). (B) Chromosomal mapping of $\operatorname{Tr} G P$ genes. Chromosomal bands of $T$. rangeli (DOG-82) were separated by CHEF as described in [12]. Lanes: 1, ethidium bromide stained gel; 2, blot after hybridization. Molecular sizes in kilobases (kb). (C) Northern blot analysis of the $\operatorname{Tr} G P$ with total RNA from T. rangeli epimastigotes. Molecular sizes in kilobases (kb). (D) Identification of $T$. rangeli TrGP native protein by western blot. Proteins from lysates of parasites were separated by SDS-PAGE and transferred to Immobilon-P (Millipore) membranes. Filters were blocked with a solution of 5\% nonfat dry milk in TBS (50 mM Tris, pH $8.0,150 \mathrm{mM} \mathrm{NaCl})$, incubated with $\mathrm{TrGP}^{\mathrm{Nterm}}$ antiserum, and the binding of antisera was revealed with alkaline phosphatase-conjugated goat anti-rabbit antibodies and the chromogen 3,3'diaminobenzidine. Extracts proteins are from parasite isolates and stages: $T$. rangeli epimastigotes: M/HOM/VE/03/CARMEN HERNANDEZ (lane 1) and M/HOM/VE/98/ALBA (lane 2), T. cruzi M/HOM/VE/92/YBM metacyclic trypomastigotes (lane 3). Molecular sizes in kilodaltons (kDa).

three $T$. rangeli isolates, and epimastigotes and trypomastigotes extracts from one $T$. cruzi strain. The result of these experiments revealed that the antiserum recognized two protein bands with molecular masses of 77 and $45 \mathrm{kDa}$ in the three $T$. rangeli samples (Fig. 2D shows two of them, lanes 1 and 2), but failed to react with the $T$. cruzi one (Fig. 2D, lane 
3). Pre-immune rabbit serum did not react with any T. rangeli proteins (not shown). The $77 \mathrm{kDa}$ band was slightly higher than the expected size, opening the possibility that the telomeric $\operatorname{Tr} G P$ is in fact a truncated form of a gp85-like protein, and/or that the native protein undergoes post-translational modifications that alter its molecular mass. It is possible that the smaller $45 \mathrm{kDa}$ band is a degradation product.

In summary, in this work we characterized an ORF encoding for a protein with high identity with members of $T$. cruzi gp85/trans-sialidase family. Although the gene is expressed in $T$. rangeli epimastigotes cells, at present we do not know its role in the parasite life cycle. Presence of gp 85/trans-sialidase in $T$. rangeli suggests that these genes were present in a common ancestor with $T$. cruzi. However, in T. cruzi, gp 85 genes suffered an expansion and adopted important roles in invasiveness and infectivity and also became a structural part of its telomeres $[3,19,20]$. The high epitopic variation of $T$. cruzi gp85 proteins has been pointed out as the cause of an anergic $\mathrm{CD} 4^{+} \mathrm{T}$ cell response that hampers an effective host attack against the parasite [3]. In contrast, since T. rangeli does not enter mammalian cells and its presence is considered harmless to the vertebrate host [21], gp85-like proteins may play a different role. The fact that the $\operatorname{Tr} G P$ gene is located next to the telomeres makes us wonder whether the presence of surface proteins genes at this position is a universal feature in all trypanosomes. Efforts are under way to determine the function of TrGP in the biology of $T$. rangeli.

\section{Acknowledgements}

This work is supported by grants from CDCHT-UCLA 025-ME-2002 and FONACIT S1-2002000542 to MAC, FONACIT-G-99000036 and CDCHT-ULA-C-1016-00-07AA to NA, FONACIT-G-9900035 to JLR. Mrs. Sharon Sumpter for revising the English of the MS.

\section{References}

[1] Colli W. trans-sialidase: a unique enzyme activity discovered in the protozoan Trypanosoma cruzi. FASEB J 1993;7:1257-64.

[2] Cross GAM, Takle GB. The surface trans-sialidase family of Trypanosoma cruzi. Annu Rev Microbiol 1993;47:385-411.

[3] Frasch ACC. Functional diversity in the trans-sialidase and mucin families in Trypanosoma cruzi. Parasitol Today 2000;16:282-6.

[4] Pontes de Carvalho LC, Tomlinson S, Nussenzweig V. Trypanosoma rangeli sialidase lacks trans-sialidase activity. Mol Biochem Parasitol 1993;62:19-26.
[5] Buschiazzo A, Campetella O, Frasch ACC. Trypanosoma rangeli sialidase: cloning, expression and similarity to T. cruzi transsialidase. Glycobiology 1997;7:1167-73.

[6] Buschiazzo A, Cremona ML, Campetella O, Frasch ACC, Sanchez DO. Sequence of a Trypanosoma rangeli gene closely related to Trypanosoma cruzi trans-sialidase. Mol Biochem Parasitol 1993;62:115-6.

[7] Buschiazzo A, Tavares GA, Campetella O, et al. Structural basis of sialyltransferase activity in trypanosomal sialidases. EMBO J 2000;19:16-24.

[8] Paris G, Ratier L, Amaya MF, Nguyen T, Alzari PM, Frasch ACC. A sialidase mutant displaying trans-sialidase activity. J Mol Biol 2005;345:923-34.

[9] Saldaña A, Harrias RA, Örn A, Monroy C, Ortega-Barria E, Sousa OE. Antigenic significance of a Trypanosoma rangeli sialidase. J Parasitol 2002;88:697-701.

[10] Giordano R, Fouts DL, Tewari D, Colli W, Manning JE, Alves MJM Cloning of a surface membrane glycoprotein specific for the infective form of Trypanosoma cruzi having adhesive properties to laminin. J Biol Chem 1999;274:3461-8.

[11] Magdesian MH, Giordano R, Ulrich H, et al. Infection by Trypanosoma cruzi Identification of a parasite ligand and its host cell receptor. J Biol Chem 2001;276:19382-9.

[12] Chiurillo MA, Peralta A, Ramirez JL. Comparative study of Trypanosoma rangeli and Trypanosoma cruzi telomeres. Mol Biochem Parasitol 2002;120:305-8.

[13] Kahn S, Van Voorhis WC, Eisen H. The major 85-kDa surface antigen of the mammalian form of Trypanosoma cruzi is encoded by large heterogeneous family of simultaneously expressed genes. J Exp Med 1990;172:589-97.

[14] Ruef BJ, Dawson BD, Devanusu T, Fouts DL, Manning JE. Expression and evolution of the T. cruzi trypomastigote surface antigen multigene family. Mol Biochem Parasitol 1994;63:109-20.

[15] Low HP, Tarleton RL. Molecular cloning of the gene encoding the $83 \mathrm{kDa}$ amastigote surface protein and its identification as a member of Trypanosoma cruzi sialidase superfamily. Mol Biochem Parasitol 1997;88:137-49.

[16] Santos AM, Garg N, Tarleton RL. The identification and molecular characterization of Trypanosoma cruzi amastigote surface protein1, a member of the trans-sialidase gene superfamily. Mol Biochem Parasitol 1997;85:1-11.

[17] Weston D, Patel B, Van Voorhis WC. Virulence in Trypanosoma cruzi infection correlates with the expression of a distinct family of sialidase superfamily genes. Mol Biochem Parasitol 1999;98:105-16.

[18] Harlow Ed, Lane D. Antibodies: A Laboratory Manual. Cold Spring Harbor: Cold Spring Harbor Laboratory Press; 1988.

[19] Chiurillo MA, Cano I, Da Silveira JF, Ramirez JL. Organization of telomeric and sub-telomeric regions of chromosomes from the protozoan parasite Trypanosoma cruzi. Mol Biochem Parasitol 1999;100:173-83.

[20] Dong K, Chiurillo MA, El-Sayed N, et al. Telomere and subtelomere of Trypanosoma cruzi chromosomes are enriched in (pseudo)genes of retrotransposon hot spot and transialidase-like gene families: the origins of T. cruzi telomeres. Gene 2005;346:153-61.

[21] Añez N, Velandia J, Rodríguez MA. Estudios sobre Trypanosoma rangeli Tejera VIII. Respuesta a las infecciones en dos mamíferos. Mem Inst Oswaldo Cruz 1985;80:149-53. 